\title{
Characterization of Vanadium and Sulfur Containing Compounds of Kazakhstan Petroleum Vacuum Residuum
}

\author{
Yerdos Ongarbayev ${ }^{1,2,3^{*}}$, Shynar Oteuli1,2, Yerbol Tileuberdi ${ }^{1,2}$, Yahe Zhang ${ }^{4}$, Fang Zheng ${ }^{4}$, \\ Quan Shi ${ }^{4}$

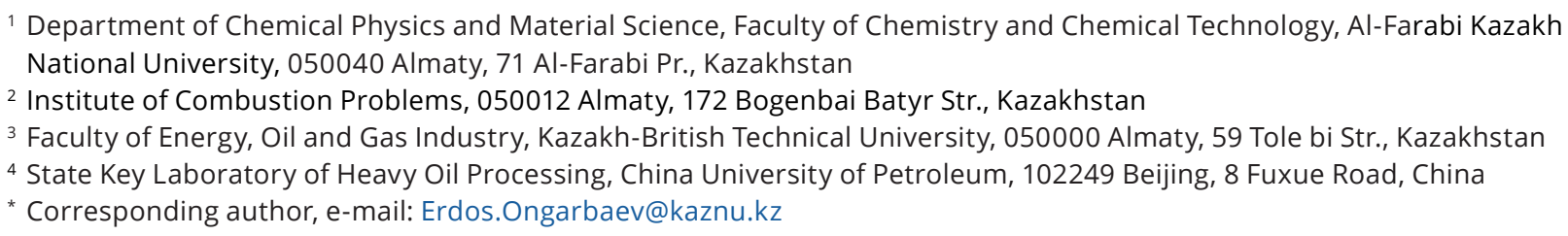

Received: 04 December 2020, Accepted: 18 March 2021, Published online: 02 Augustus 2021

\begin{abstract}
In the paper, bulk property and chemical composition of Kazakhstan vacuum residuum were characterized. Sulfides and thiophenes were selectively isolated from the residuum and characterized by Fourier transform ion cyclotron resonance mass spectrometry (FT-ICR MS). Molecular weights of the sulfur compounds were varied from 150 to $800 \mathrm{Da}$ and $\mathrm{S}_{1}, \mathrm{~S}_{2}, \mathrm{O}_{1} \mathrm{~S}_{1}, \mathrm{O}_{2} \mathrm{~S}_{1}, \mathrm{~N}_{1} \mathrm{~S}_{1}$ class species were assigned in the heavy oil derived methylsulfonium. Vanadyl porphyrins characterized by positive-ion electrospray ionization and FT-ICR MS, which showed that etioporphyrins (ETIO) $\left(\mathrm{C}_{n} \mathrm{H}_{2 n-28} \mathrm{~N}_{4} \mathrm{~V}_{1} \mathrm{O}_{1}\right.$, corresponding to DBE = 17) and deoxophylloerythroetioporphyrins (DPEP) $\left(\mathrm{C}_{\mathrm{n}} \mathrm{H}_{2 \mathrm{n}-30} \mathrm{~N}_{4} \mathrm{~V}_{1} \mathrm{O}_{1}\right.$, corresponding to $\left.\mathrm{DBE}=18\right)$. It should be noted that the vanadyl porphyrins were most abundant.
\end{abstract}

Keywords

characterization, petroleum vacuum residuum, sulfur compounds, vanadyl porphyrins, heavy oil residues

\section{Introduction}

In connection with the growing consumption of petroleum and petroleum products, the gradual depletion of exploited oil fields, heavy hydrocarbon raw materials are becoming in demand in the global economy. Nowadays, the hydrocarbon reserves are concentrated in heavy oils and the world's heavy oil reserves are amount to more than 6 trillion barrels [1].

The main task of the oil refining industry is deepen oil refining in order to increase the production of high-quality motor fuels and raw materials for petrochemicals. It is unprofitable to process heavy oil according to the classical scheme in order to producing fuel, because it contains low amount of light fractions. High content of sulfur and resin-asphaltene substances in the heavy oil also reduces the equipment life of oil refineries. Rational use of heavy hydrocarbons, as source of energy and raw materials for the production of motor fuels, lubricants, bitumen, coke and variety of petrochemical products, has been a major national task for the Republic of Kazakhstan [2].
The main reserve for the effective solution of this problem is the heavy or high-molecular part of oil, which makes up $25 \%-30 \%$ of the crude oil, received for processing with the modern technology of oil refining and is called "heavy oil residues". More than half of the heavy oil residues are containing resin-asphaltene substances. In this regard, the problem of studying the composition, structure, properties, the main directions of chemical processing and the use of heavy oil residues are great scientific importance and practical relevance.

In connection with the growth of deep processing of oil refining, as well as the involvement of oils rich in non-hydrocarbon components in the refining processes, the solution of problems associated with the presence of hetero-organic compounds in crude oil are becoming increasingly important. Due to the presence of these components, the technology of oil refining is significantly complicated, the period of validity and selectivity of catalysts decrease, and the operational characteristics of the products obtained 
deteriorate [3]. In addition, a substantial part of hetero-organic compounds in the fuels are burned and emit oxides of sulfur, nitrogen, and metals into the atmosphere, which causes irreparable harm to the environment.

Methods for the separation of mixtures based on the application of new principles have been developed [4, 5], which makes it possible to quickly obtain quantitative data on the composition of petroleum fractions [6]. The most important chemical types and structural features of many heteroatoms have been characterized [7], as well as some patterns of individual classes of these compounds [8]. However, despite all this, further in-depth studies of the composition and structure of petroleum heteroatoms are needed, as they study the researchers face almost insurmountable difficulties due to the complexity and variability of the oil composition, the extraordinary molecular diversity of hetero-organic compounds, and the lack of effective, accessible analytical methods. Analytical material on methods for determining heteroatomic components in petroleum and petroleum products is scattered, uncooperative, not subjected to statistical processing, and in need of some systematization. Considering the future development of analytical methods, specialists do not see a single universal method capable of ensuring the solution of all analytical tasks to determine hetero-organic compounds in oils and oil products and satisfies all requirements at once (high reproducibility, wide range of content determination, simultaneous determination of a wide range of elements, possibility of using the method on-site field work). The lack of certified standards, calibration systems, unified methods for the preliminary preparation of petroleum and petroleum products for analysis are one of the difficulties in ensuring the accuracy of the analysis. The possibility of systematization of analytical data is also hampered by the different quantitative and qualitative composition of hetero-organic compounds in oils, which vary depending on the region of oil production, the conditions of transportation, storage and processing of oil.

In this regard, the development of effective methods for studying the composition and properties of hetero-organic compounds, as well as methods for their concentration and isolation in the native form, is an important scientific and technical challenge.

Fourier transform ion cyclotron resonance mass spectrometry (FT-ICR MS) has been used to characterize the composition of highly complex hydrocarbon mixtures. FT-ICR MS has the highest mass resolution and mass accuracy, which enables the assignment of a unique elemental composition to each peak in the mass spectrum [9].
The distribution of vanadium compounds in the petroleum vacuum residuum and their transformations in hydrodemetallization (HDM) were investigated [10]. The results indicated that a highly active HDM catalyst should possess a highly active hydrogenesis property and macropore size distribution for the different $\mathrm{V}$ compounds removed.

In [11] the heteroatom classes and molecular structures of nitrogen compounds in vacuum residue are characterized by the electrospray ionization (ESI) FT-ICR MS combined with the Fourier transform infrared (FT-IR) spectroscopy.

Compositional changes of Colombian vacuum residue and its supercritical fluid extraction fractionation (SFEF) subfractions were analysed by positive- and negative mode electrospray (ESI) coupled with FT-ICR MS [12]. A set of 200 representative molecules for a vacuum residue fractionated with molecular distillation was obtained [13]. Information obtained was employed for reconstruction and generation of set molecules that represents the original vacuum residue by contribution methods.

In [14] Gel Permeation Chromatography (GPC) and Simulated Distillation (SD) results combined for the first time to characterize very heavy hydrocarbon samples. The molecular weight of a number of vacuum residue and their SARA fractions typical of the Barrancabermeja refinery in Colombia were determined using the Gel Permeation Chromatography (GPC), Vapor Pressure Osmometry (VPO) and Simulated Distillation at High Temperature adjusted to the Gamma distribution function [15].

The paper [3] explores physical and chemical properties and composition of heavy oil from Yarega field and its vacuum residue. An integrated process flow diagram for heavy Yarega oil refinement has been proposed, including preliminary deasphalting and demetallization, hydrotreatment, delayed coking and thermodestructive processes or gasification.

The paper [16] presents an alternative technique for selective extraction of asphaltenes from two Brazilian vacuum residues and compares these results to the ones observed using the IP-143 standard methodology. The extracted fraction was characterized by ${ }^{1} \mathrm{H}$ NMR and TG/DTG, revealing that the chemical species extracted using different techniques exhibited very small differences in composition but similar thermal behavior.

${ }^{1} \mathrm{H}$ NMR spectroscopy in combination with statistical methods was used to study vacuum residues and vacuum gas oils from 32 crude oils of different origin [17]. Pseudo two-dimensional DOSY ${ }^{1} \mathrm{H}$ NMR experiments were used to assess the composition and structural properties of asphaltenes in a selected crude oil and its vacuum residue 
on the basis of their different hydrodynamic behavior and translational diffusion coefficients. DOSY spectra showed the presence of several asphaltene aggregates differing in size and interactions they formed.

In this work, the composition of components and the structure of vanadium and sulfur compounds of the heavy vacuum residuum of the Pavlodar Petrochemical Plant are determined for the first time.

\section{Experimental}

\subsection{Samples and reagents}

A heavy vacuum residuum was obtained from Pavlodar Petrochemical Plant LLP (Kazakhstan), which is the raw material of the delayed coking unit. Dichloromethane (DCM), n-hexane (n-C 6 , n-heptane $\left(n-C_{7}\right)$, toluene, methanol, ethyl alcohol and acetonitrile were distilled for purification before use. $\mathrm{CH}_{3} \mathrm{I}, \mathrm{AgBF}_{4}$, 4-dimethylaminopyridine (DMAP), 7-azaindole were purchased from J\&K Chemical Ltd.

\subsection{Saturates/Aromatics/Resins/Asphaltenes separation} The vacuum residuum of $1 \mathrm{~g}$ was dissolved with $50 \mathrm{~mL}$ heptane, followed by filtting the mixture which was refluxed for $1 \mathrm{~h}$. The substance that cannot be dissolved by heptane was regarded as asphaltenes. The maltenes was condensed by rotary evaporation to $5 \mathrm{~mL}$ for further separation. $50 \mathrm{~g}$ neutral alumina (100-200 mesh, activated at $500{ }^{\circ} \mathrm{C}$ for $6 \mathrm{~h}, 1 \mathrm{wt} . \%$ water added) were loaded into a glass column and wetted with n-heptane. The maltenes added into column and eluted by heptane $(80 \mathrm{~mL})$, toluene $(80 \mathrm{~mL})$ to obtain saturates, aromatics, respectively. The process followed Chinese industry standard method SH/T 0509-92, equivalent to ASTM D2007-93.

\subsection{Selective separation of thiophenes and sulfides}

One gram vacuum residuum was dissolved in $10 \mathrm{~mL}$ of $\mathrm{DCM}$ and 5 mol equiv of $\mathrm{AgBF}_{4}$ and 15 mol equiv MeI (based on the sulfur content of the sample) were added successively. The mixture were stirred in the dark at room temperature for $24 \mathrm{~h}$ and the procedure was repeated once in order to enhance the reaction. Filtration was carried out to remove the yellow precipitate of $\mathrm{AgI}$ generated in the process. Then add $50 \mathrm{~g}$ of anhydrous $\mathrm{Na}_{2} \mathrm{SO}_{4}$ to the mixture obtained to confirm products were adsorbed to the surface of sodium sulfate uniformly. The DCM was completely evaporred, by rotary evaporation. Afterwards, the sample was transferred to a clean glass column, unreacted oil and sulfonium salt was eluted by n-hexane respectively. 10 mol equiv of 7-azaindole was added to the sulfonium salts. Reaction was carried out at room temperature for $24 \mathrm{~h}$. The thiophenic compounds was extracted by n-hexane. Similarly, 10 mol equiv of DMAP was added to the raffinate, then the sulfides was obtained.

\subsection{ESI FT-ICR MS analysis}

The asphaltenes and sulfonium salt were analyzed using a Bruker Apex-Ultra FT-ICR MS equipped with a $9.4 \mathrm{~T}$ superconducting magnet. The sample solution was infused via an Apollo II electrospray ionization source at $200 \mu \mathrm{l} / \mathrm{h}$ using a syringe pump. The operating conditions for positive ion formation were a $-3.5 \mathrm{kV}$ emitter voltage, $-4.0 \mathrm{kV}$ capillary column front end voltage, and $320 \mathrm{~V}$ capillary column end voltage. Ions were accumulated for $0.01 \mathrm{~s}$ in a hexapole with $2.4 \mathrm{~V}$ DC voltage and $300 \mathrm{Vp}-\mathrm{p}$ RF amplitude. The optimized mass for Q1 was $200 \mathrm{Da}$. An argonfilled hexapole collision pool was operated at $5 \mathrm{MHz}$ and $400 \mathrm{Vp}-\mathrm{p}$ RF amplitude, in which ions accumulated for $0.2 \mathrm{~s}$. The extraction period for ions from the hexapole to the ICR cell was set to $1.3 \mathrm{~ms}$. The RF excitation was attenuated at $11.75 \mathrm{~dB}$ and used to excite ions over the range of 150-800 Da. Four M data sets were acquired. A number of 64 cans FT-ICR data sets were coadded to enhance the signal-to-noise ratio and dynamic range.

\subsection{Mass calibration and data analysis}

The mass spectrometer was calibrated using sodium formate. Peaks with a relative abundance greater than 5 times the standard deviation of the baseline noise were exported to a spreadsheet. Data analysis was performed using custom software, which has been described elsewhere [18]. The data analysis was performed by selecting a two-mass scale-expanded segment in the middle of spectra, followed by detailed identification of each peak. The peak of at least one of each heteroatom class species was arbitrarily selected as a reference. Species with the same heteroatom class and its isotopes with different values by DBE and carbon number were searched within a set \pm 0.001 Kendrick mass defect KMD tolerance.

Experimental errors for all presented data range $\pm 0.01-0.1$.

\section{Results and discussion}

Physical and chemical properties of the vacuum residuum are listed in Table 1. The residuum has a high density and low $\mathrm{H} / \mathrm{C}$ ratio, relative high oxygen and sulfur contents. The asphaltene and metal contents are not high comparing with heavy oils that have similar density. Regardless the mixing of different raw materials, the oil 
Table 1 Properties and elemental contents of the vacuum residuum

\begin{tabular}{lcc}
\hline Properties & Values & Methods \\
\hline Density $\left(20{ }^{\circ} \mathrm{C}, \mathrm{kg} / \mathrm{m}^{3}\right)$ & 981.0 & ASTM D1298-12b \\
Coking (wt.\%) & 14.0 & ASTM D189-06 \\
Ash content (wt.\%) & 0.02 & ASTM \\
& & D482-19 \\
Water content (wt.\%) & up to 0.1 & ASTM D6304-20 \\
\hline Boiling point $\left({ }^{\circ} \mathrm{C}\right)$ & 380 & ASTM D1160-18 \\
\hline Group composition & & \\
Saturates (wt.\%) & 21.8 & \\
Aromatics (wt.\%) & 50.5 & SH/T 0509-92 \\
Resins (wt.\%) & 23.9 & \\
Asphaltenes (wt.\%) & 3.8 & \\
\hline Elemental composition & & \\
C (wt.\%) & 85.49 & \\
H (wt.\%) & 10.76 & \\
O (wt.\%) & 1.35 & \\
N (wt.\%) & 0.59 & \\
S (wt.\%) & 2.68 & \\
H/C & 1.51 & \\
Vanadium (wppm) & 10.76 & \\
Nickel (wppm) & 1.35 & \\
Iron (wppm) & 0.59 & \\
\hline
\end{tabular}

shows a characteristic of marine facies origin, maturited, and biodegraded crude oil. The low vanadium and nickel contents implies the biodegradation is not severe.

Sulfur compound is one of the most important concerns of heavy oil. In the last decade, using high resolution FT-ICR MS, the molecular composition of sulfur compounds in heavy petroleum has been achieved. However, the molecular composition of sulfur compounds as a whole is not satisfying for the understanding of chemical transformation properties of oil, because different isomer structures of sulfur compounds, for example, sulfides and thiophenes could have largely different reactivities. Hence, the characterization of different sulfur compounds is needed. An effective separation method has been developed [19] and has been successfully used for processing crude oils and their fractions.

Table 2 shows the content of separated sulfide and thiophene fractions, which consists of $26.32 \%$ and $22.23 \%$ of the oil, respectively. The yields were not include polar molecules with sulfidic and thiophenic moities.

Table 2 The content of sulfur-containing compounds of vacuum residuum

\begin{tabular}{lcc}
\hline Compounds & Content $(\mathrm{mg} / \mathrm{L})$ & Content $(\%)$ \\
\hline Thiophenes & 156.3 & 22.23 \\
Sulphides & 186.0 & 26.32 \\
Polar compounds & 503.4 & 42.73 \\
Non-polar compounds & 31.2 & 8.83 \\
\hline
\end{tabular}

Fig. 1 shows the broad-band positive-ion ESI FT-ICR mass spectrum of the methyl derivatization products of the heavy oil residue and its two sulfur fractions. The data indicates that the molecular weight of sulfur compounds in heavy oil residue varied from 150 to $800 \mathrm{Da}$. The peak identifications were obtained without subtraction of the mass of derivatization group. The results from expanded mass scale spectra at $\mathrm{m} / \mathrm{z} 425$ shows sulfur compounds of $\mathrm{C}_{29} \mathrm{H}_{45} \mathrm{~S}_{1}(\mathrm{DBE}=8)$ and $\mathrm{C}_{28} \mathrm{H}_{57} \mathrm{~S}_{1}(\mathrm{DBE}=1)$.

Fig. 2 shows the relative abundance of heteroatoms assigned from the positive-ion ESI FT-ICR mass-spectra of the methylated vacuum residuum, sulfide and thiophene. Relative abundance is defined as the magnitude of each peak divided by the magnitudes of all identified peaks (exclude the isotopic peaks) in the MS spectrum. The vacuum residuum has highest relative abundance of $\mathrm{S}_{1}$ class species, followed by $\mathrm{S}_{2}, \mathrm{O}_{1} \mathrm{~S}_{1}, \mathrm{~N}_{1} \mathrm{~S}_{1}, \mathrm{O}_{2} \mathrm{~S}_{1}$. The distribution of heteroatoms in sulfide fraction and thiophene fraction are similar to that of the vacuum residuum. It is worth noting that the relative abundance of $\mathrm{S}_{2}$ class species in thiophene fraction is higher than sulfide fraction, which implies that both of the sulfur atoms in the $\mathrm{S}_{2}$ class species are in the form of thiophene.

Fig. 3 shows the distribution plots of DBE versus carbon number for $\mathrm{S}_{1}$ class species from the positive-ion ESI FT-ICR MS spectra of methylated vacuum residuum and its sulfide and thiophene fractions. Generally, benzothiophenes and/or dibenzothiophenes are the most abundant sulfur

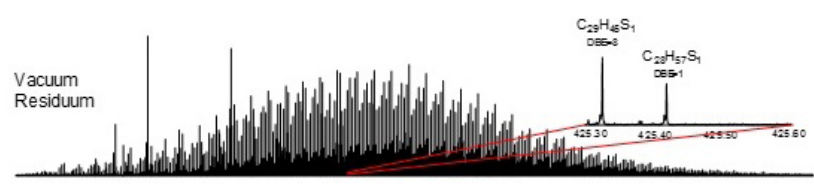

(a)

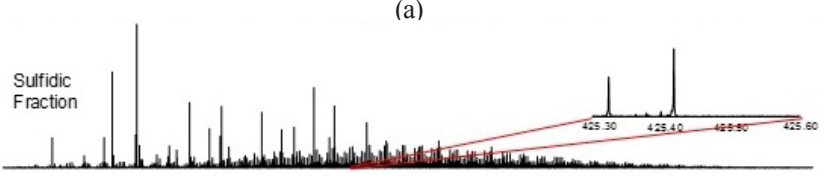

(b)

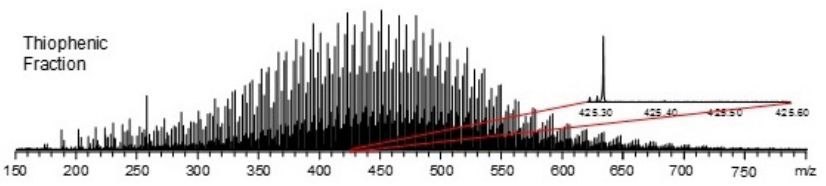

(c)

Fig. 1 Broad-band positive-ion ESI FT-ICR MS spectra of the methyl derivatization products of vacuum residuum fraction (a), its sulfidic (b) and thiophenic (c) fractions. The inset shows the expanded mass spectra at $m / z 425$. 


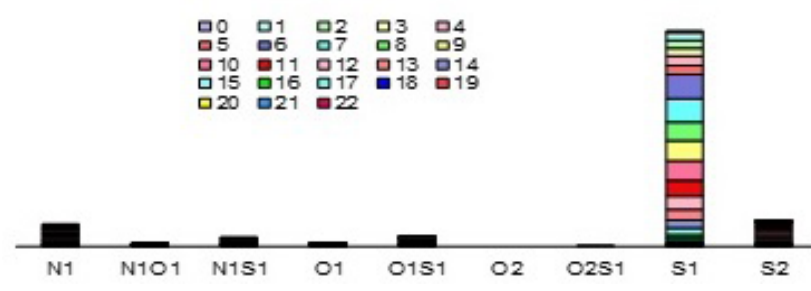

(a)

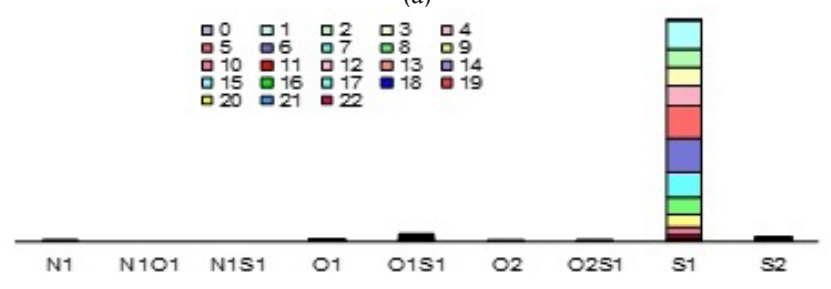

(b)

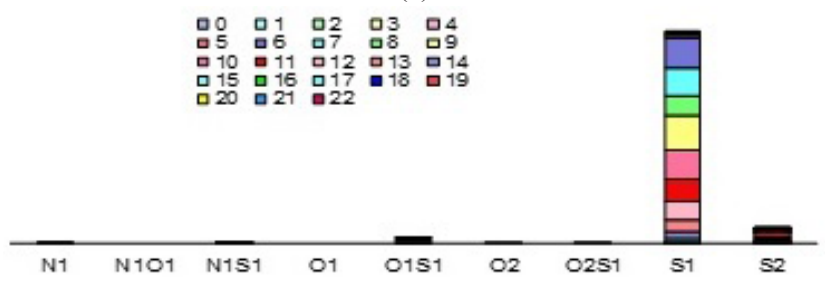

(c)

Fig. 2 Relative abundance of heteroatom class assigned from the methylated heavy oil fraction (a), its sulfide (b) and thiophene (c)

fractions derived from positive-ion ESI FT-ICR MS spectra

compounds in petroleum, which have DBE values of 6 and 9, respectively. Fig. 3 (a) displays that the most abundant $S_{1}$ class species varied over a wide range of DBE (1-22) and carbon number (10-55). Furthermore, the $\mathrm{S}_{1}$ class species with carbon numbers of 20-40 and DBE values from 6 to 12 have the highest abundance, which indicated thiophene series compounds were dominant in sulfur compounds. For the sulfide fraction (Fig. 3 (c)), compounds with DBE value of 1 should be sulfides with 1 naphthenic ring, while the compounds with DBE values of 5-7, which having high relative abundance, are likely aromatic sulfides. Fig. 3 (c) shows the sulfur compound ditribution of thiophene fraction. As mentioned above, DBE values of 6-12 correspond to benzothiophenes, dibenzothiophenes and benzonaphthothiophenes. The absence of DBE $=1$ series indicates the successful separation of sulfides from thiophenes.

The positive-ion broad-band ESI FT-ICR MS spectrum of asphaltene in the vacuum residue shows that its molecular weight varied from 250 to $800 \mathrm{Da}$. The inset shows an expanded mass spectrum at $m / z$ 380-400, which contain the highest relative abundance of $\mathrm{O}_{4}$ class species, such as $\mathrm{C}_{24} \mathrm{H}_{39} \mathrm{O}_{4}$.

Fig. 4 shows the distribution plots of DBE versus carbon number for vanadyl porphyrins from positive-ion ESI FT-ICR MS spectrum of the asphaltenes. The double-bond

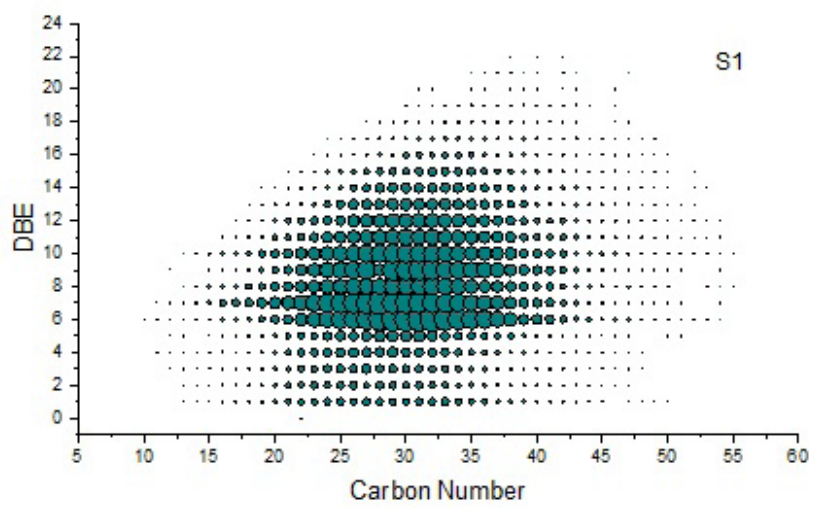

(a)

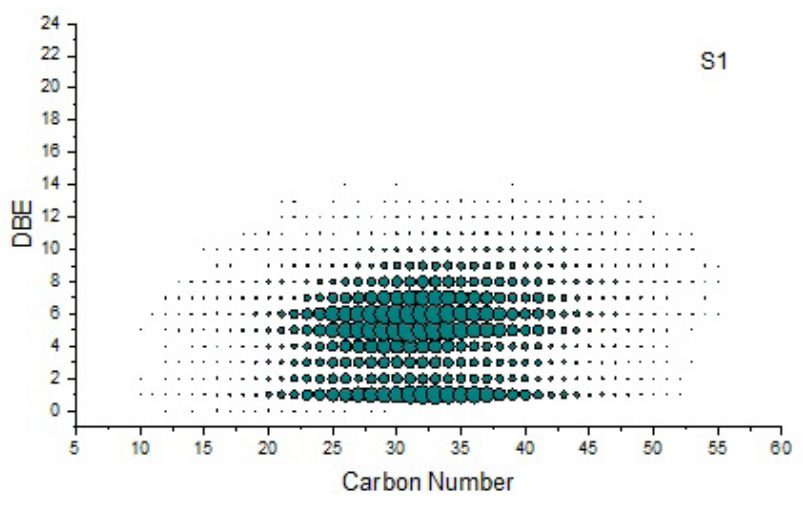

(b)

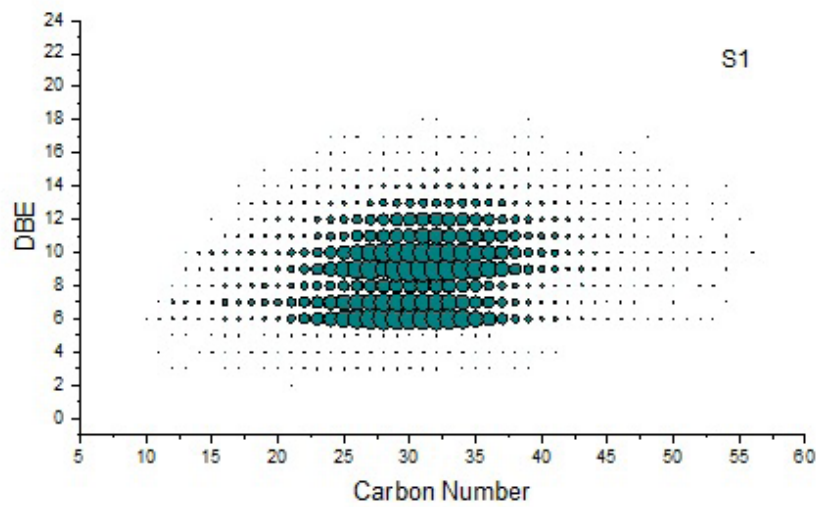

(c)

Fig. 3 Plots of DBE as a function of the carbon number for $\mathrm{S}_{1}$ class species in methylated samples of heavy oil residuum (a), its sulfidic (b) and thiophenic (c) fractions from positive-ion ESI FT-ICR MS.

equivalent (DBE) is defined as the number of double bonds plus rings. The double bond in the vanadyl group $(\mathrm{V}=\mathrm{O})$ is not counted in DBE, which only co-valent double bonds connected with carbon atoms are considered. Alkyl porphyrins containing the main structure $\mathrm{N}_{4} \mathrm{VO}$ have been discovered. As Fig. 4 shows the $\mathrm{N}_{4} \mathrm{VO}$ class has DBE value of 17-24 and carbon number of 24-44. The etioporphyrins (ETIO) $\left(\mathrm{C}_{\mathrm{n}} \mathrm{H}_{2 \mathrm{n}-28} \mathrm{~N}_{4} \mathrm{~V}_{1} \mathrm{O}_{1}\right.$, corresponding to $\mathrm{DBE}=17$ ) and deoxophylloerythroetioporphyrins (DPEP) $\left(\mathrm{C}_{\mathrm{n}} \mathrm{H}_{2 \mathrm{n}-30} \mathrm{~N}_{4} \mathrm{~V}_{1} \mathrm{O}_{1}\right.$, corresponding to $\left.\mathrm{DBE}=18\right)$ are 


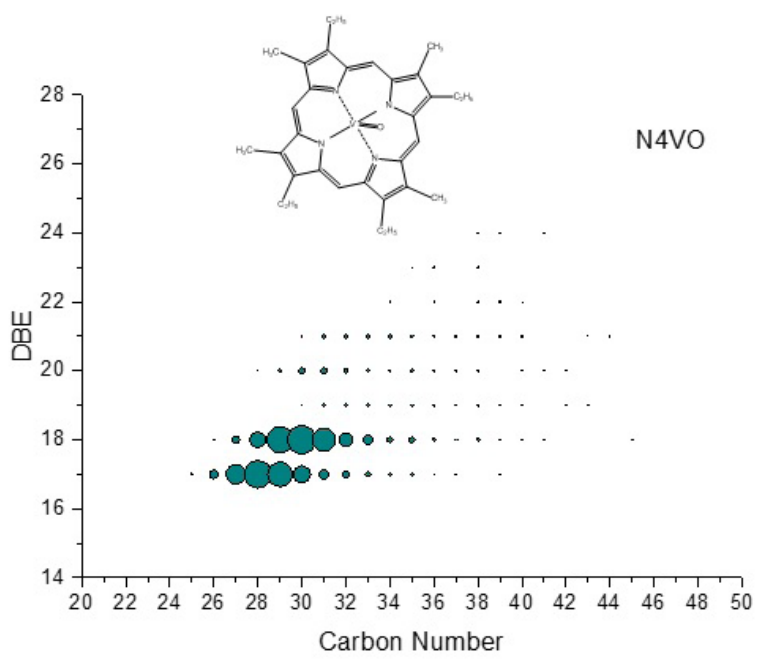

Fig. 4 Relative abundance plot of DBE versus carbon number for vanadyl porphyrins assigned from positive-ion ESI FT-ICR mass spectrum of the asphaltenes

the most abundant vanadium porphyrin detected in this sample, which consists with the previous research [20]. In the composition of the vacuum residuum, etioporphyrins have a center of mass at $\mathrm{C}_{28}$, which corresponds to the composition of $\mathrm{C}_{28} \mathrm{H}_{29} \mathrm{~N}_{4} \mathrm{VO}$ while phylloporphyrins have a maximum content at $\mathrm{C}_{30}$ corresponding to the formula $\mathrm{C}_{30} \mathrm{H}_{31} \mathrm{~N}_{4} \mathrm{VO}$.

\section{Conclusion}

Detailed characterization of Kazakhstan vacuum residuum compounds were carried out. Actually, the elemental

\section{References}

[1] Santos, R. G., Loh, W., Bannwart A. C., Trevisan, O. V. "An overview of heavy oil properties and its recovery and transportation methods", Brazilian Journal of Chemical Engineering, 31(3), pp. 571-590, 2014.

https://doi.org/10.1590/0104-6632.20140313s00001853

[2] Ongarbayev, Y., Oteuli, Sh., Tileuberdi, Y., Maldybaev G., Nurzhanova, S. "Demetallization and desulfurization of heavy oil residues by adsorbents", Petroleum Science and Technology, 37(9), pp. 1045-1052, 2019.

https://doi.org/10.1080/10916466.2019.1570257

[3] Kondrasheva, N. K., Khorkhe, A. "Effect of chemical composition and quality of heavy Yarega oil on selection of appropriate processing technology", Journal of Mining Institute, 222, pp. 833838, 2016.

https://doi.org/10.18454/pmi.2016.6.833

[4] Desbène, P. L., Jauseau-Pierre, N., Desmazières, B., Basselier, J. J. "Analytical study of various heavy oil residues using a transalkylation reaction", Chromatographia, 26(1), pp. 70-76, 1988.

https://doi.org/10.1007/BF02268127 and component composition of vacuum residuum is determined. According to the results that etioporphyrins (ETIO) $\left(\mathrm{C}_{\mathrm{n}} \mathrm{H}_{2 \mathrm{n}-28} \mathrm{~N}_{4} \mathrm{~V}_{1} \mathrm{O}_{1}\right.$, corresponding to $\left.\mathrm{DBE}=17\right)$ and deoxophylloerythroetioporphyrins (DPEP) $\left(\mathrm{C}_{\mathrm{n}} \mathrm{H}_{2 \mathrm{n}-30} \mathrm{~N}_{4} \mathrm{~V}_{1} \mathrm{O}_{1}\right.$, corresponding to $\mathrm{DBE}=18$ ) were the most abundant vanadium porphyrin in this vacuum residuum by characterization of FT-ICR MS. The thiophene and sulfide fractions based composition of sulfur-containing compounds were characterized by FT-ICR MS after the process of methylation and demethylation. In fact, the content of sulfides and thiophenes are $26.32 \%$ and $22.23 \%$ of mass weight in vacuum residuum, respectively. The sulfide compounds has a range of DBE (1-5) corresponding to naphthenic sulfides or aromatic sulfides and DBE (6-8) corresponding to aryl sulfide compounds probably. In thiophenic fraction, DBE value of 6-12 should be correspond to benzothiophenes, dibenzothiophenes and naphthalene benzothiophenes. Based on the results of the analyzes, it is recommended to carry out preliminary demetallization and desulfurization of vacuum residuum, followed by coking to obtain coke.

\section{Acknowledgment}

This research is funded by the Science Committee of the Ministry of Education and Science of the Republic of Kazakhstan, Grant No. AP08856559 on titled "Development of sorbents based on shungite rocks for cleaning oil-contaminated soils".

[5] Ferreira, C., Tayakout-Fayolle, M., Guibard, I., Lemos, F., Toulhoat, H., Ramôa Ribeiro, F. "Hydrodesulfurization and hydrodemetallization of different origin vacuum residues: Characterization and reactivity", Fuel, 98, pp. 218-228, 2012. https://doi.org/10.1016/j.fuel.2012.03.054

[6] McKenna, A. M. "Detailed Characterization of Heavy Crude Oils and Asphaltenes by Ultrahigh Resolution Fourier Transform Ion Cyclotron resonance Mass Spectrometry", PhD Dissertation, Florida State University, 2009.

[7] Wang, Z., Fingas, M., Sergy, G. "Chemical Characterization of Crude Oil Residues from an Arctic Beach by GC/MS and GC/FID", Environmental Science \& Technology, 29(10), pp. 2622-2631, 1995. https://doi.org/10.1021/es00010a025

[8] Zheng, F., Chung, W., Palmisano, E., Dong, D., Shi, Q., Xu Z., Chung, K. H. "Molecular characterization of polar heteroatom species in oilsands bitumen-derived vacuum residue fractions by Fourier transform ion cyclotron resonance mass spectrometry", Petroleum Science, 16(5), pp. 1196-1207, 2019. https://doi.org/10.1007/s12182-019-0345-3 
[9] Zhao, X., Liu, Y., Xu, C., Yan, Y., Zhang, Y., Zhang, Q., Zhao, S., Chung, K., Gray, M. R., Shi, Q. "Separation and Characterization of Vanadyl Porphyrins in Venezuela Orinoco Heavy Crude Oil", Energy \& Fuels, 27(6), pp. 2874--2882, 2013. https://doi.org/10.1021/ef400161p

[10] Liu, T., Lu, J., Zhao, X., Zhou, Y., Wei, Q., Xu, C., Zhang, Y., Ding, S., Zhang, T., Tao, X., Ju, L., Shi, Q. "Distribution of Vanadium Compounds in Petroleum Vacuum Residuum and Their Transformations in Hydrodemetallization", Energy \& Fuels, 29(4), pp. 2089-2096, 2015. https://doi.org/10.1021/ef502352q

[11] Xiaobo, C., Teng, L., Yibin, L., Honghong, S., Chaohe, Y., Chunyi, L. "Characterization of Nitrogen Compounds in Vacuum Residue and Their Structure Comparison with Coker Gas Oil", China Petroleum Processing and Petrochemical Technology, 16(3), pp. 33-41, 2014. [online] Available at: http://www.chinarefining.com/EN/Y2014/ V16/I03/33 [Accessed: 15 March 2021]

[12] Arenas-Diaz, J. P., Palacio, D. C., Ramirez, C. X., Cabanzo, R., Guzmán, A., Mejía-Ospino, E. "Chemical Characterization of Polar Species in Colombian Vacuum Residue and Its Supercritical Fluid Extraction Subfractions Using Electrospray Ionization FT-ICR Mass Spectrometry", Chemical Engineering Transactions, 57, pp. 1603-1608, 2017. https://doi.org/10.3303/CET1757268

[13] Ramirez, C. X., Torres, J. E., Palacio Lozano, D. C., ArenasDiaz, J. P., Mejia-Ospino, E., Kafarov V., Guzmán, A. "Molecular Representation of Molecular Distillation Cuts of Vacuum Residue by Spectrometry Ultra-High Resolution and Conventional Analytic", Chemical Engineering Transactions, 57, pp. 1069-1074, 2017. https://doi.org/10.3303/CET1757179

[14] Azinfar, B., Zirrahi, M., Hassanzadeh, H., Abedi, J. "Characterization of heavy crude oils and residues using combined Gel Permeation Chromatography and simulated distillation", Fuel, 233, pp. 885-893, 2018.

https://doi.org/10.1016/j.fuel.2018.06.110
[15] León, A. Y., Parra, M. J. "Determination of Molecular Weight of Vacuum Residue and Their Sara Fractions", Ciencia, Tecnología y Futuro, 4(2), pp. 101-112, 2010.

[16] Silva, F. B., Guimarães, M. J. O. C., Seidl, P. R., Garcia, M. E. F. "Extraction and characterization (compositional and thermal) of asphaltenes from Brazilian vacuum residues", Brazilian Journal of Petroleum and Gas, 7(3), pp. 107-118, 2013. https://doi.org/10.5419/bjpg2013-0009

[17] Vuković, J. P., Novak, P., Plavec, J., Friedrich, M., Pajc, L. M., Hrenar, T. "NMR and Chemometric Characterization of Vacuum Residues and Vacuum Gas Oils from Crude Oils of Different Origin", Croatia Chemica Acta, 88(1), pp. 89-95, 2015. https://doi.org/10.5562/cca2612

[18] Shi, Q., Zhao, S., Xu, Z., Chung, K. H., Zhang Y., Xu, C. "Distribution of Acids and Neutral Nitrogen Compounds in a Chinese Crude Oil and Its Fractions: Characterized by Negative-Ion Electrospray Ionization Fourier Transform Ion Cyclotron Resonance Mass Spectrometry", Energy \& Fuels, 24(7), pp. 4005-4011, 2010. https://doi.org/10.1021/ef1004557

[19] Wang, M., Zhao, S., Chung, K. H., Xu C., Shi, Q. "Approach for Selective Separation of Thiophenic and Sulfidic Sulfur Compounds from Petroleum by Methylation/Demethylation", Analytical Chemistry, 87(2), pp. 1083-1088, 2015. https://doi.org/10.1021/ac503670k

[20] Ongarbayev, Y., Oteuli, Sh., Tileuberdi, Y., Maldybaev, G., Nurzhanova, S. "Demetallization of heavy vacuum residuum by titanium-vanadium zeolite adsorbents", Studia Universitatis Babes-Bolyai Chemia, 65(1), pp. 219-231, 2020. https://doi.org/10.24193/subbchem.2020.1.17 